\title{
Mesotelioma peritoneal deciduoide
}

\section{Peritoneal mesotelioma deciduoid}

\author{
S. Kennedy ${ }^{1} \quad$ L. Sánchez ${ }^{1}$ \\ ${ }^{1}$ Cátedra y Servicio de Imágenes, Hospital de Clínicas, San Lorenzo, \\ Paraguay \\ Rev Argent Radiol 2018;82:45-47.
}

Address for correspondence Dra. S. Kennedy, MD, Cátedra y Servicio de Imágenes, Hospital de Clínicas, San Lorenzo, Paraguay (e-mail: saritah_kennedy@hotmail.com).
Estimados Editores,

El mesotelioma es una neoplasia maligna, poco frecuente. Los pacientes que no siguen un tratamiento tienen una sobrevida media de 5 a 12 meses. ${ }^{1,2}$ Afecta, por lo general, a los hombres, con una edad media de 65 años, sin embargo puede manifestarse a cualquier edad. ${ }^{3}$

El tumor se origina de las células mesoteliales que tapizan la pleura, el peritoneo, el pericardio y la túnica vaginal. También existe la afectación peritoneal aislada que constituye un $30 \%$ de los casos, o en combinación con afectación pleural. ${ }^{4}$

Aproximadamente un $50 \%$ de los pacientes con mesotelioma peritoneal presentan un antecedente de exposición al asbesto. Se han visto, además, otros factores de riesgo como la exposición a heroinita, al contraste radiológico Thorotrast y la infección por el virus 40 de los simios. ${ }^{3,5}$ Los hallazgos imagenológicos, especialmente los obtenidos por tomografía computada (TC), son importantes para la evaluación preoperatoria y el pronóstico del paciente.

Hemos presentado un caso de esa rara patología en un paciente de sexo masculino, 59 años de profesión plomeroalbañil, ex tabaquista de larga data (20 cigarrillos al día), que consultó en la sala de urgencias por un cuadro de dolor abdominal difuso, de inicio brusco, acompañado de astenia, náuseas, sensación de pesadez y leve pérdida de peso de tres meses de evolución.

Se realizó un examen ecográfico abdominal (-Fig. 1) y un estudio tomográfico en tórax y abdomen (-Fig. 2 ), donde se observó una gran formación sólida que comprometía todo el peritoneo, rodeando estructuras vasculares e intestinales, sin evidencia de infiltración a las mismas. Se procedió a realizar una biopsia laparoscópica cuyo resultado fue mesotelioma peritoneal de tipo deciduoide.

La sintomatología del mesotelioma peritoneal es gradual e inespecífica. Incluye: pérdida de peso, dolor y aumento del volumen abdominal, resultando en un diagnóstico tardío y dificultoso. ${ }^{3}$ Existen dos tipos de mesotelioma peritoneal según los hallazgos del estudio tomográfico. El tipo "seco", presenta uno o múltiples nódulos con escasa o nula presencia de líquido. El tipo "húmedo", presenta pequeños nódulos difusamente distribuidos e importante ascitis. ${ }^{1,3,6}$ En el estudio tomográfico, el mesotelioma peritoneal típico se manifiesta como una masa sólida, con densidad de partes blandas, que realza tras la inyección de contraste, localizada en el mesenterio, epiplón o el peritoneo. Otra manera de presentación es en forma de una masa infiltrante o múltiples nódulos. ${ }^{1}$ Suele extenderse a las superficies serosas, ejercer efecto de masa e invadir por contigüidad órganos adyacentes. ${ }^{1}$ Las calcificaciones no son muy frecuentes, contrariamente a lo que ocurre en el mesotelioma pleural, por lo que, si existen, otras causas de masas peritoneales deberán ser consideradas. ${ }^{4,5}$

Existen escasos datos publicados sobre los hallazgos ecográficos y en resonancia magnética. ${ }^{1}$ No se puede confirmar el diagnóstico de mesotelioma peritoneal a través de la imagen a pesar de que las características observadas sugieran esa entidad. Para llegar al diagnóstico, se aconseja realizar una biopsia laparoscópica; o bien, múltiples biopsias bajo guía tomográfica o ecográfica. ${ }^{1}$

Los diagnósticos diferenciales a tener en cuenta son: masas sólidas mesentéricas o peritoneales, entre ellas, las de causa secundaria, como las derivadas del ovario, colon y estómago. Las calcificaciones y la importante ascitis son datos de valor, debido a ser poco frecuentes en esa entidad. Otras patologías tumorales como el linfoma, el pseudomixoma peritonei, la mesenteritis esclerosante, el quiste de inclusión peritoneal y el tumor carcinoide, deben ser considerados. Entre las enfermedades infecciosas, la peritonitis tuberculosa también puede presentarse como masa sólida mesentérica. ${ }^{1}$

La terapéutica es limitada y poco efectiva a consecuencia del diagnóstico tardío. El tratamiento de elección es la terapia combinada, cirugía más quimioterapia o radioterapia, con la received

March 2, 2017

accepted

August 16, 2017

published online

March 23, 2018
DOI https://doi.org/

10.1055/s-0038-1637031. ISSN 1852-9992.
Copyright $\odot$ 2019, Sociedad Argentina de Radiología. Publicado por Thieme Revinter Publicações Ltda., Rio de Janeiro, Brazil. Todos los derechos reservados.
License terms

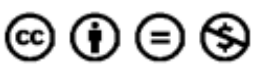




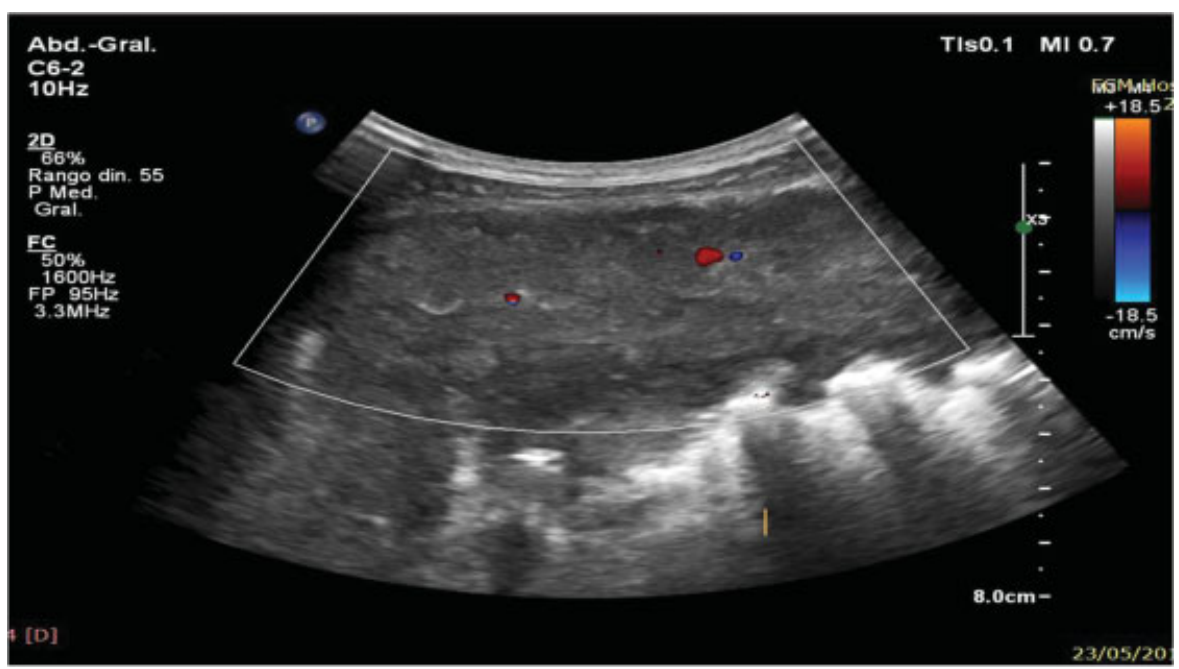

Fig. 1 Ecografía abdominal donde se demuestra una gran formación hipoecogénica, heterogénea, de contornos irregulares y escaso flujo al Doppler color, que ocupa extensamente la cavidad abdominal.

cual se alcanza una supervivencia media de 55 meses, aproximadamente. ${ }^{1}$

La tomografía computada es indispensable para la planificación quirúrgica, ${ }^{1}$ ya que es necesario determinar el estado de los órganos adyacentes para decidir la posible resección de los mismos. El colon y el hígado son los órganos abdominales involucrados con mayor frecuencia. La infiltración del intestino delgado complicado con obstrucción o nódulos tumorales adyacentes a la pared del mismo son indicadores de un mal pronóstico. Si no se
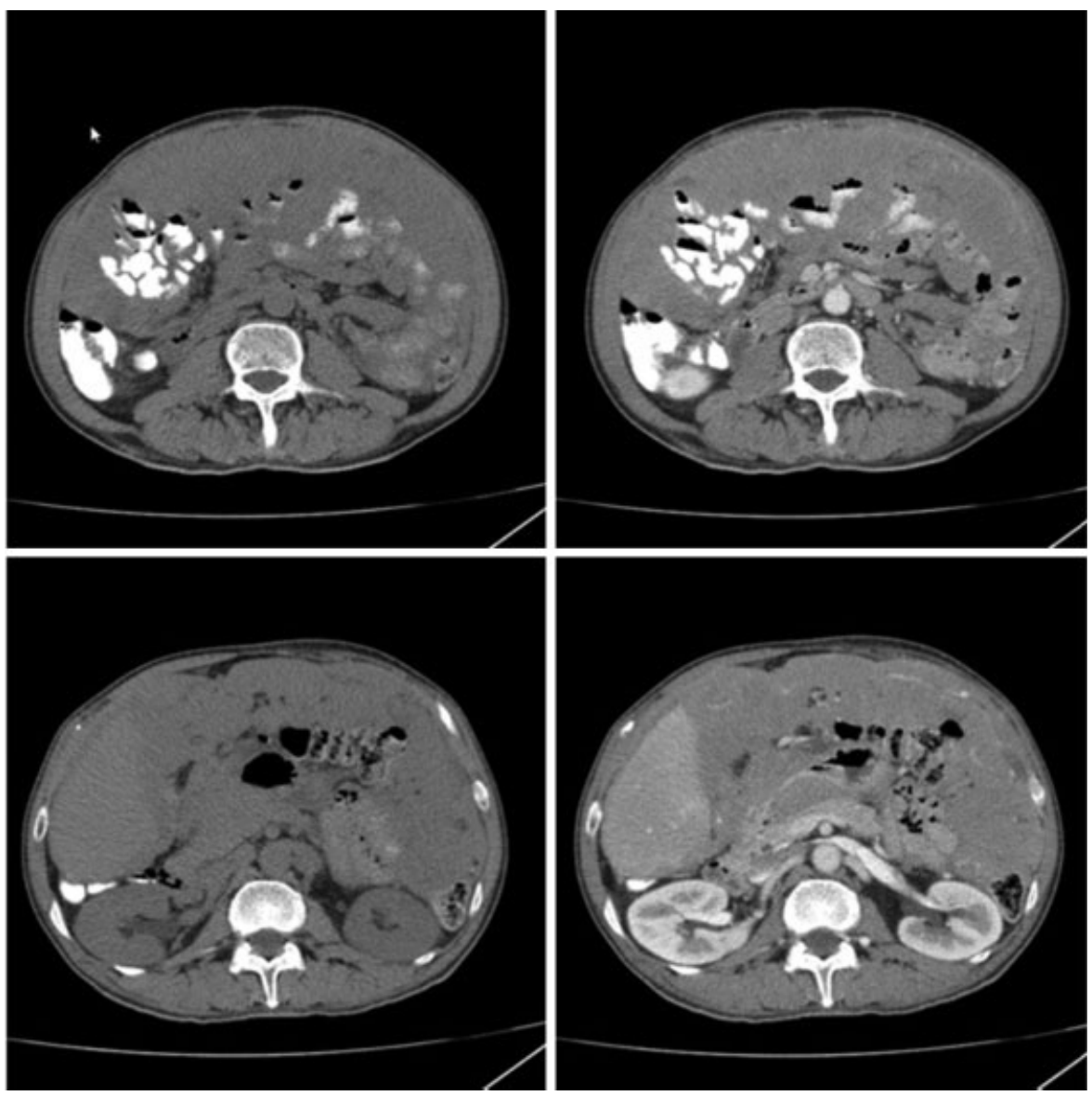

Fig. 2 Cortes axiales de tomografía computada de abdomen sin y con contraste endovenoso, donde se evidencia extensa masa de densidad tisular que compromete todo el peritoneo, rodeando a los órganos y estructuras vasculares de la cavidad abdominal. No presenta plano de clivaje con la pared de las asas intestinales e infiltra la pared abdominal anterior a izquierda. Presenta leve realce homogéneo tras la inyección del medio de contraste. No se evidencian adenomegalias en los cortes tomograficos presentados. 
evidencian signos de obstrucción, y el intestino delgado y el mesenterio pueden ser compartimentalizados, se puede realizar una cirugía paliativa o citorreductora en combinación con la quimioterapia. ${ }^{1,4}$

Saludan atentamente, los autores.

\section{Confidencialidad de los datos}

Los autores declaran que han seguido los protocolos de su centro de trabajo sobre la publicación de datos de pacientes y que todos los pacientes incluidos en el estudio han recibido información suficiente y han dado su consentimiento informado por escrito para participar en dicho estudio.

Conflicto de intereses

Los autores del trabajo declaran no tener ningún conflicto de intereses.

\section{Bibliografía}

1 Busch JM, Kruskal JB, Wu B; Armed Forces Institute of Pathology. Best cases from the AFIP. Malignant peritoneal mesothelioma. Radiographics 2002;22(06):1511-1515

2 Wilches C, Rivero O, Aguirre D. Evaluación por imágenes de las neoplasias peritoneales primarias y secundarias. Rev Colomb Radiol. 2010;21:1-11

3 Torrejón Reyes PN, Frisancho O, Gómez A, Yábar A. [Malignant peritoneal mesothelioma]. Rev Gastroenterol Peru 2010;30(01): $82-87$

4 Levy AD, Arnáiz J, Shaw JC, Sobin LH. From the archives of the AFIP: primary peritoneal tumors: imaging features with pathologic correlation. Radiographics 2008;28(02):583-607, quiz 621-622

5 Pickhardt PJ, Bhalla S. Primary neoplasms of peritoneal and subperitoneal origin: CT findings. Radiographics 2005;25(04): 983-995

6 Heiken J, Menias C, Elsayes K. Joseph. "Pared abdominal y cavidad peritoneal”. En: Body TC con correlación RM. Madrid: Marban; 2007:1101-1153 